\title{
As Três Abordagens Necessárias para o Estudo das Ciências Sociais
}

\author{
Domingos Crosseti Branda* \\ Felipe Rosa da Silva
}

\begin{abstract}
Resumo: O positivismo lógico é invalido para o estudo das ciências sociais. Faz-se necessário, portanto, a utilização de uma metodologia válida. Ela consiste em estudar conjuntamente três abordagens necessárias de uma mesma realidade humana: a teórica, a histórico-interpretativa e a ética. Tal metodologia, inclusive, soluciona os problemas da gênese da ética, a dicotomia existente entre o pensamento de Hayek e Rothbard: ética evolucionária derivada da história ou ética universal construída através do axioma da ação. Trabalhar, separar e relacionar as 3 abordagens: eis a metodologia completa a ser utilizada no estudo das ciências sociais.
\end{abstract}

Palavras-Chave: Método. Significação. Compreensão timológica. Ética objetiva.

\section{The Three Approaches Required for the Study of Social Sciences}

\begin{abstract}
Logical positivism is invalid for the study of social sciences. Therefore, it is necessary to use a valid methodology. It consists of studying together three necessary approaches to a same human reality: theoretical, historical-interpretative and ethical. Besides, this methodology addresses the issue of the genesis of ethics, the dichotomy between the thoughts of Hayek and Rothbard: evolutionary ethics derived from history or universal ethics built from the axiom of action. Working, separating and listing those three approaches: that is the complete methodology to be used in the study of social sciences.
\end{abstract}

Keywords: Method. Significance. Thymology. Objective ethics.

Classificação JEL: B41, B53

\footnotetext{
" Domingos Crosseti Branda é bacharel em Administração e Ciências Econômicas pela Universidade Federal de Santa Maria (UFSM). Pós-graduado em Economia de la Escuela Austriaca pela Universidad Rey Juan Carlos (Madri).domingosbranda@gmail.com
}

** Felipe Rosa da Silva é Bacharel em Ciências Econômicas pela Universidade Federal de Santa Maria e mestrando do Programa de Pós Graduação em Economia e Desenvolvimento (PPGE\&D) da UFSM. felipersdt@yahoo.com.br 


\section{I - INTRODUÇÃo}

Em um artigo anterior ${ }^{1}$, abordou-se a invalidez do positivismo lógico nas ciências sociais, expondo o argumento da invalidez e propondo um método válido. Agora, queremos aprofundar a proposição do método além da praxiologia e história, acrescentando o aspecto ético ${ }^{2}$. Trata-se de

1 BRANDA, Domingos Crosseti. A Invalidez do Positivismo Lógico nas Ciências Sociais. Instituto Ludwig von Mises Brasil. Disponível em: <http:// www.mises.org.br/Article.aspx?id=1737> .

${ }^{2}$ Segundo os antigos gregos, as ciências tinham três grandes grupos de estudo: a ética, a física e a lógica. A éticaeafísicatinhamambastantoum componenteformal quanto empírico (prático); a lógica era considerada como um campo de conhecimento puramente formal (KANT, Immanuel. Fundamentação da Metafísica dos Costumes. São Paulo: Barcarolla, 2009). A ética, ou ciências sociais, proporcionava a compreensão dos utilizar três abordagens conjuntas da mesma realidade humana

Essa metodologia das três abordagens conjuntas tem sua gênese na concepção do professor Huerta de Soto para o estudo das ciências sociais, publicada no Cap. VII de Estudios de economia política. Na verdade, este capítulo é uma critica a afirmação do profes-

fenômenos sociais, enquanto a física ou ciências naturais possibilitavam a explicação dos fenômenos naturais. A natureza das investigações era radicalmente distinta em virtude do componente volitivo do ser humano, o que implicava em fundamentos epistemológicos e metodologias completamente distintas. Utilizar a metodologia das ciências naturais nas sociais implica em total desconhecimento da natureza humana e em uma concepção metodológica errônea para estas ciências. É tão absurdo quanto considerar o inverso: o aspecto volitivo humano no estudo dos fenômenos da natureza.

\section{Esquema em Três Níveis para o Estudo das Ciências Sociais}

Realidade Histórica da Humanidade (a ser interpretada de maneira única)

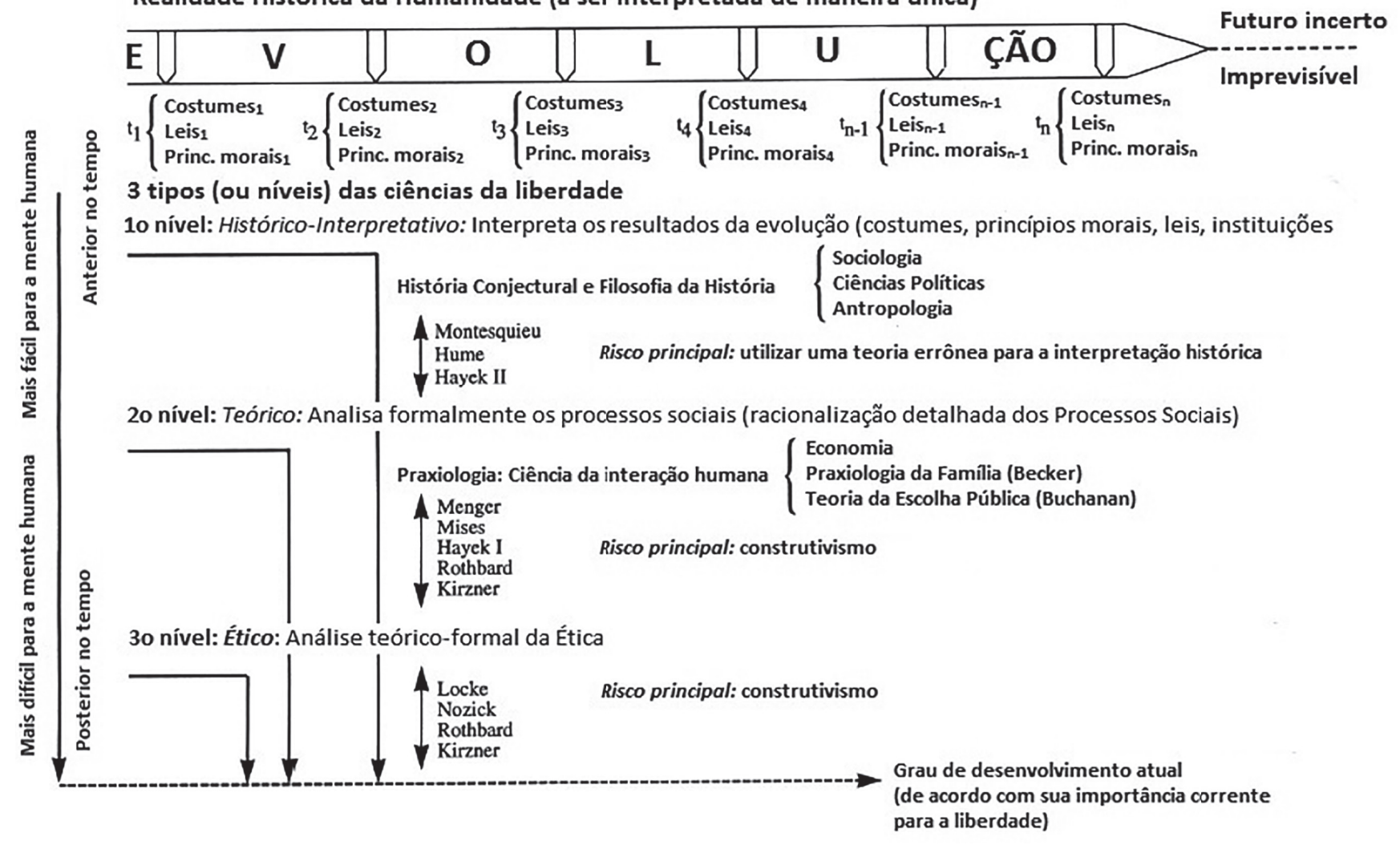

Figura 1 - Esquema de três níveis para o estudo das ciências sociais.

Fonte: HUERTA DE SOTO, Jesús. Estudios de Economía Política. Madrid: Unión Editorial, 2004. p. 106. 
sor Hayek quanto à sua não aceitação de um sistema ético universal ${ }^{3}$.

A metodologia proposta pelo professor Huerta de Soto aborda três níveis distintos da mesma realidade humana, complementares e que se enriquecem mutuamente: o primeiro nível é denominado histórico-interpretativo e interpreta os resultados da evolução social; o segundo nível é denominado teórico e analisa formalmente os processos sociais; por último, um terceiro nível consiste na análise formal da ética. A metodologia adequada para o estudo das ciências sociais consiste em trabalhar nos três níveis, separá-los e relacioná-los. Vejamos esse conceito de forma esquemática, a seguir:

Concordamos em trabalhar conjuntamente com os três níveis, mas discordamos do modo de relação entre eles. Tal modo apresenta certo distanciamento entre o nível ético e o histórico-interpretativo, justamente a preocupação central do professor Huerta de Soto. Consideramos mais correta uma relação de forma piramidal, onde o cume é a abordagem teórica, ficando na base as abordagens histórico-interpretativa e ética. Todas continuam se relacionando entre si.

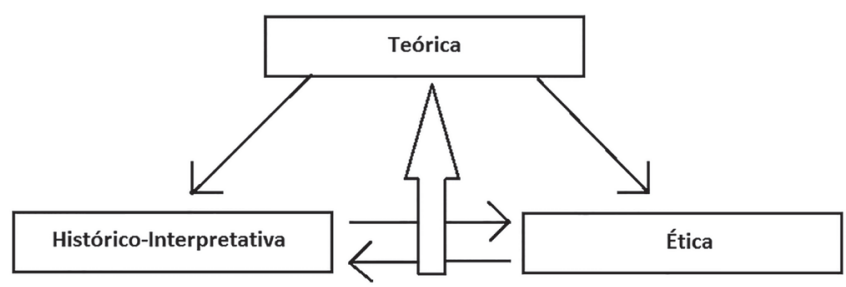

Figura 2 - As 3 abordagens necessárias.

Fonte: Elaboração própria.

Tal modelo piramidal apresenta três diferenças em relação ao modelo de referência. A primeira e mais notória é a importância dada à abordagem teórica, que possibilita a

\footnotetext{
3 "[...] se a civilização é fruto de mudanças inesperadas e graduais nos esquemas morais, por muito que isso nos desagrade, estaremos obrigados a concluir que não está ao alcance do homem nenhum sistema ético que possa gozar de validade universal" (HAYEK, F. A. Principios de un Orden Social Liberal. 2a. ed. Madrid: Unión Editorial, 2010. p. 52-53).
}

significação ${ }^{45}$ dos demais aspectos. A segunda é a abordagem histórico-interpretativa e a ética em um mesmo patamar. A terceira diferença é que o produto da análise entre as abordagens histórico-interpretativa e ética possibilita a formação dos conceitos relevantes para o desenvolvimento teórico, realimentando o método.

Uma vez exposta a concepção elementar da metodologia, vejamos cada abordagem em essência.

\section{II - As Três Abordagens NECEsSÁRIAS}

\section{1 - Abordagem Teórica}

A abordagem teórica formal da realidade humana consiste na praxiologia ${ }^{6}$. É a abordagem precursora por ter um caráter epistemológico apriorístico ${ }^{7}$. Segundo Ludwig von Mises (1881-1973), sem uma ciência apriorística, não é possível compreender a realidade da ação humana. O poder que a razão tem de esclarecer, através do simples raciocínio, as características essenciais da ação, é consequência do fato de que a ação é um produto da razão. Os teoremas que o raciocínio praxiológico consegue estabelecer adequadamente são não apenas impecavelmente verdadeiros e incontes-

4 O significado precede qualquer exercício de raciocínio lógico, ou seja, de nada adianta um rigor lógico no estabelecimento de uma teoria formal se os significados elementares ou conceitos não estiverem definidos e devidamente validados.

${ }^{5}$ Não cabe aqui superar o atual empasse epistemológico da Escola Austríaca proposto por Zanotti, mas apenas estabelecer o ponto de partida para o desenvolvimento do estudo em ciências sociais. Ver: ZANOTTI, G. J. Uma Proposta para Superar o Atual Impasse Epistemológico da Escola Austríaca. Mises: Revista Interdisciplinar de Filosofia, Direito e Economia. v. I, n. 1 (2013): 27-32.

${ }^{6}$ MISES, Ludwig von. Ação Humana: Um Tratado de Economia. 3a. ed. São Paulo: Instituto Mises Brasil, 2010. p. 23.

7 Condições intelectuais de pensamento necessárias e inevitáveis, anteriores a qualquer momento real de concepção e experiência. 
táveis como os teoremas matemáticos. Mais ainda, referem-se, com a plena rigidez de sua certeza apodítica e de sua incontestabilidade, à realidade da ação tal como se apresenta na vida e na história.

Essa certeza advém do caráter axiomático da ação humana - a proposição de que os humanos agem para sair de uma situação desconfortável para uma situação confortável ou de menor desconforto - que é uma real proposição sintética apriorística. A proposição de que os humanos agem não pode ser refutada, uma vez que tal negação seria, ela própria, uma ação; a verdade dessa afirmação não pode ser revogada.

Tendo este axioma como ponto de parti$\mathrm{da}$, o desenvolvimento teórico da praxiologia segundo Mises consiste no raciocínio lógico-dedutivo que leva a teoremas específicos. Tais teoremas são construídos introduzindo-se, em lugar adequado na cadeia lógico-dedutiva, conceitos relevantes advindos da experiência histórica humana, os quais já têm uma teoria prévia à sua espera para serem interpretados e, consequentemente, para construir teoremas mais específicos.

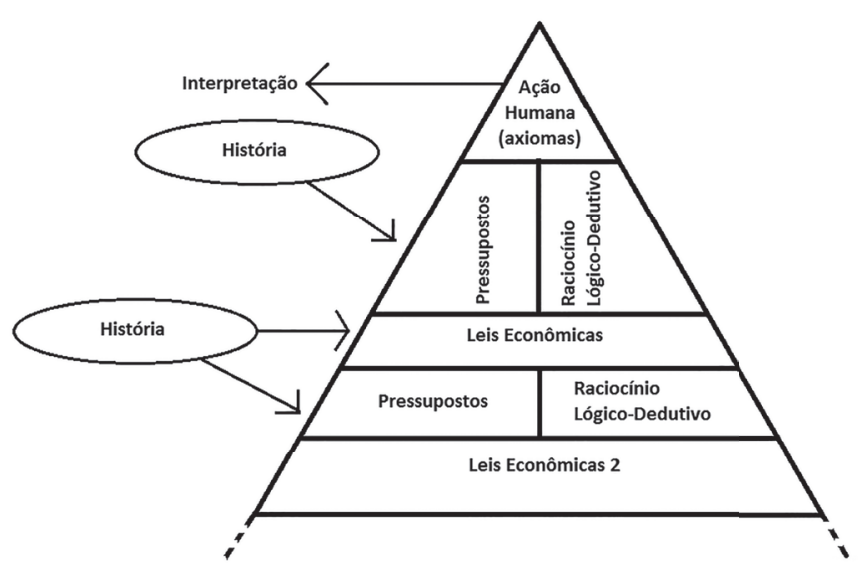

Figura 3 - Ilustração do método de desenvolvimento da parte formal da Ciência Econômica. Fonte: Elaboração própria.

O grande campo da praxiologia pode ser subdividido segundo os objetos de estudo e conceitos relevantes no desenvolvimento da teoria, o que vai delimitar a economia, o direito, a administração, a sociologia e afins.
Em analogia, é como se as ciências sociais fosse uma pirâmide de múltiplas faces, onde o cume é o axioma da ação humana e cada face constitui um campo de conhecimento segundo seu objeto de estudo. Vejamos o exemplo da Ciência Econômica:

\section{2 - Abordagem Histórico-Interpretativa}

A abordagem histórico-interpretativa da realidade humana é a filosofia da historia. Mises afirma que no desenvolvimento do estudo da história, os fatos sociais históricos observáveis (documentais, bibliográficos, relatos, etc.) são sempre fenômenos complexos da vida social, onde cada dado da experiência está aberto a distintas interpretações e somente pode ser interpretado através de uma teoria formal prévia e válida 8 . Entretanto, sempre remanesce no fundo de cada um de seus problemas algo que resiste à análise feita com base nos ensinamentos das outras ciências. Estas são as características singulares e peculiares a cada evento histórico e só podem ser analisadas recorrendo-se à compreensão.

Compreensão é mais o resultado da percepção intelectual do que do conhecimento factual, embora não deve nunca contradizer os ensinamentos válidos dos outros ramos do conhecimento, inclusive os das ciências naturais. A compreensão é usada por todo o mundo e é o único método apropriado para lidar com a história e com a incerteza das condições futuras, ou de qualquer situação em que o nosso conhecimento seja incompleto. É o método que todos os historiadores e todas as pessoas aplicam quando comentam eventos humanos passados ou quando tentam prever eventos futuros, por serem elas mesmas seres humanos ${ }^{9}$.

Entretanto, mesmo sendo um último reduto quando as outras ciências não trazem mais respostas acerca da história, a compreensão apresenta um limitante epistemológico.

\footnotetext{
${ }^{8}$ MISES. Ação Humana: Um Tratado de Economia.

${ }^{9}$ GREAVES, P. Mises Made Easier. New York: Books, 1974.
} 
Ela possibilita o conhecimento dos juízos e ações de outras pessoas no passado, mas não possibilita o conhecimento do juízo de valor e ações futuras de outras pessoas. E as pessoas precisam desse conhecimento porque as ações humanas são sempre voltadas para o futuro. A solução deste problema epistemológico da compreensão está em associá-la à experiência timológica ${ }^{10}$, que é o que sabemos sobre os juízos de valor, as ações que determinam e as reações que determinadas ações suscitam em outras pessoas, criando o que se denomina compreensão timológica ${ }^{11}$.

A compreensão timológica é o processo de conexão entre praxiologia e história. Trata-se do conhecimento de circunstâncias históricas particulares, o que possibilita as predições das ações humanas. A compreensão timológica possibilita ao ser humano a enumeração de fatores determinantes em um evento, bem como a importância de cada fator na sua determinação ${ }^{12}$.

\footnotetext{
${ }^{10}$ Palavra derivada do grego thymos, que se refere ao centro das emoções e capacidade mental do ser vivo que torna possível o pensamento, a vontade e o sentimento. Segundo Wilhelm Dilthey, a timologia é a ciência que se ocupa dos pensamentos humanos, ideias, juízos de valor e suas relações com o mundo externo. Algo diferente da psicologia experimental. Nesse sentido, ver: MISES, Ludwig von. Teoría e Historia. Madrid: Unión Editorial, 2003. p. 320. Conforme Mises (Idem, p. 334), ressaltou: "a timologia [...] lida com as atividades mentais dos homens que determinam suas ações. Lida com os processos mentais que resultam em um determinado tipo de comportamento, com as reações da mente às condições do ambiente do indivíduo".
}

11 Tal expressão não é meramente inventada. Huerta de Soto utiliza-a na explicação do estudo e filosofia da história. Ver: HUERTA DE SOTO, Jesús. Estudios de Economía Política. 2a. ed. Madrid: Unión Editorial, 2004.

${ }^{12}$ É importante ressaltar que, no âmbito da compreensão timológica, a noção de nexo causal encontra-se intrinsecamente complementar: "O homem tem condições de agir porque tem a capacidade de descobrir relações causais que determinam mudanças e transformações no universo. Ação requer e pressupõe a existência da causalidade. Só pode agir o homem que percebe o mundo à luz da causalidade. Neste sentido é que podemos dizer que a causalidade é um requisito

\section{3 - Abordagem Ética}

A abordagem ética é fruto de uma interpretação histórica ou deriva da teoria formal? Essa dicotomia existe dentro da própria Escola Austríaca de Economia e é representada pelas concepções de Friedrich Hayek (18991992) e Murray N. Rothbard (1926-1995), os dois principais discípulos de Mises. O primeiro afirma não aceitar uma concepção ética universal (conforme exposto na introdução), enquanto o segundo a concebe ${ }^{13}$ com base na praxiologia:

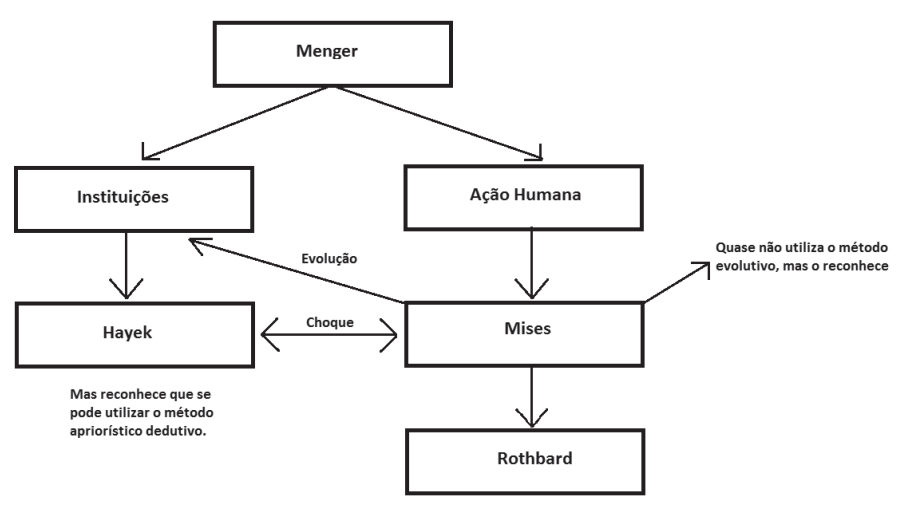

\section{Figura 4 - Enfoques de estudo de Hayek e Rothbard.}

Fonte: Elaboração própria, adaptado de MESSEGUER, R. La Teoría Evolutiva de las Instituciones. 2a. ed. Madrid: Unión Editorial, 2009.

Para a elaboração de um sistema ético universal é necessário que exista um princípio ético universal independente, que seja ontológico e não fruto da evolução histórica. Há esse principio ético universal?

da ação. A categoria meios e fins pressupõe a categoria causa e efeito. Num mundo sem causalidade e sem a regularidade dos fenômenos, não haveria campo para o raciocínio humano nem para a ação humana. Um mundo assim seria um caos no qual o homem estaria perdido e não encontraria orientação ou guia. $\mathrm{O}$ homem nem é capaz de imaginar um universo caótico de tal ordem" (MISES. Ação Humana: Um Tratado de Economia. p. 47).

13 Trata-se da magnum opus do autor. ROTHBARD, Murray N. A Ética da Liberdade. São Paulo: Instituto Ludwig von Mises Brasil, 2010. 
A resposta começa no idealismo da liberdade, em contraposição ao naturalismo. O ponto fundamental destacado por Wilhelm Dilthey (1833-1911)14 é que "o espírito conhece a sua essência como diversa de toda a causalidade física"; se o homem não é determinado pela natureza, é determinado por outro aspecto volitivo: a sua própria vontade, a sua própria deliberação. O idealismo da liberdade é válido pelo simples fato de que o leitor o entende e pode escolher entre aceitá-lo ou não. E quem realiza este exercício intelectual não somente prova sua condição humana como obrigatória, mas consequentemente também advoga em favor do idealismo da liberdade, excluindo-se do naturalismo. Não há vítimas da natureza e dos impulsos fisiológicos. A própria volição humana é a causa de qualquer responsabilidade na própria conduta, embora haja o reconhecimento da influência de fatores fisiológicos.

O ser humano consegue dar significado a essa diversidade causal e à sua vontade através do apriorismo, que é uma característica ontológica. Quando o homem realiza o raciocínio apriorístico sobre si mesmo, em um processo denominado introspecção, também raciocina e adquire conhecimento apriorístico sobre a natureza humana e suas ações. E desse conhecimento apriorístico extrai o valor fundamental: o direito natural da própria existência.

Este princípio ontológico é independente da abordagem histórico-interpretativa e sendo assim, torna possível a concepção de um sistema ético universal. Tendo este princípio como ponto de partida, o desenvolvimento desse sistema consiste no raciocínio lógico-dedutivo que leva a teoremas específicos, tal qual ocorre na praxiologia. Tais teoremas são construídos introduzindo-se, em lugar adequado na cadeia lógico-dedutiva, conceitos relevantes advindos da compreensão timológica, os quais já têm uma teoria previa à sua espera para serem interpretados e,

\footnotetext{
${ }^{14}$ DILTHEY, W. Os Tipos de Concepções de Mundo. Lisboa: Edições 70, 1992. p. 46
}

consequentemente, para construir teoremas mais específicos ${ }^{15}$.

Assim, é possível construir um sistema ético universal independente da abordagem histórico-interpretativa, sendo válida a crítica à afirmação do professor Hayek citada na introdução deste artigo.

\section{III - Considerações Finais}

As três abordagens são aproximações diferentes da mesma realidade humana. São distintos, porém, complementares e se enriquecem mutuamente. A abordagem teórica é precursora pelo seu caráter apriorístico. Serve tanto para a compreensão timológica da história, como também para desenvolver um sistema ético universal. E a síntese entre a abordagem ética e histórico-interpretativa possibilita a criação de conceitos relevantes para o desenvolvimento da abordagem teórica, criando, assim, o caráter conjunto e enriquecendo o estudo.

Trabalhar as três abordagens, separá-las e relacioná-las: eis a metodologia completa a ser utilizada no estudo das ciências sociais. cos

15 Pela dedução lógica chegaremos à relação com os demais seres humanos que nos leva à seguinte conclusão: o que é eticamente válido para si, vale também para qualquer outro ser humano. Não obstante, uma máxima de conduta humana também existe. E nesse ponto Immanuel Kant já deixou o legado à ciência. Concebeu Kant à luz do idealismo da liberdade, a seguinte máxima: "Age de tal maneira que tomes a humanidade, tanto em tua pessoa quanto na pessoa de qualquer outro, sempre ao mesmo tempo como fim, nunca meramente como meio" (KANT, Immanuel. Fundamentação da Metafísica dos Costumes. p. 118). A sequência da dedução leva ao Princípio da Não Agressão, um dos princípios fundamentais do libertarianismo. Nesse sentido ver: ROTHBARD. A Ética da Liberdade. 